\title{
Determinação simultânea de teobromina, teofilina e cafeína em chás por cromatografia líquida de alta eficiência
}

\author{
Adriana Barreto Alves', Neura Bragagnolo'* \\ ${ }^{1}$ Centro de Química de Alimentos e Nutrição Aplicada - Instituto de Tecnologia de Alimentos (ITAL), ${ }^{2}$ Departamento \\ de Ciência de Alimentos, Faculdade de Engenharia de Alimentos, Universidade Estadual de Campinas
}

*Correspondência:

N. Bragagnolo

Faculdade de Engenharia de Alimentos

- UNICAMP

Depto. de Ciência de Alimentos

Caixa Postal 6121

13083-970 - Campinas, SP

E-mail: neura@fea.unicamp.br
Para a realização deste trabalho, foram analisadas 10 amostras de diferentes tipos e marcas de chás com o objetivo de se quantificar teobromina, teofilina e cafeína simultaneamente. Para tanto, otimizou-se técnica de cromatografia líquida de alta eficiência (CLAE) baseada na ISO 10095 (1992), utilizando-se coluna Inertsil ODS-3 (150x4 mm, $5 \mathrm{~mm})$, fase móvel de ácido acético 1\% + acetonitrila $(95: 5, \mathrm{v} / \mathrm{v})$, fluxo de $1 \mathrm{~mL} / \mathrm{min}$ e detector de UV/VIS ajustado em $273 \mathrm{~nm}$. Os resultados de cafeína obtidos por esse método foram comparados com os obtidos por um método espectrofotométrico de acordo com Schormüller (1970). Não houve diferença significativa nos resultados de cafeína nas amostras de chá preto obtidos pelos dois métodos. As amostras de chá preto foram as que apresentaram maiores teores de teobromina e cafeína e nenhuma das amostras apresentou quantidades significativas de teofilina.

\author{
Unitermos: \\ - Alcalóides \\ - Teobromina \\ - Teofilina \\ - Cafeína \\ - Chás \\ - CLAE
}

\section{INTRODUÇÃO}

O chá é uma das bebidas mais populares do mundo, devido a seu aroma e sabor agradáveis e também a seus efeitos sobre a saúde.

A composição química dos chás pode variar quanto a espécie, idade das folhas, estação, clima (umidade, temperatura, latitude) e condições de cultivo (solo, água, minerais, fertilizantes, entre outros) (Lin et al., 1996, 1998).

Teobromina, teofilina e cafeína são alcalóides da família das metilxantinas, um dos principais grupos constituintes das folhas de chá. A cafeína (1,3,7trimetilxantina) é o mais comum dentre os três, sendo encontrada principalmente em chás, cafés, produtos de cacau e bebidas à base de cola. Seus efeitos fisiológicos na saúde humana incluem estimulação do sistema nervoso central, dos músculos cardíacos, do sistema respiratório e da secreção de ácido gástrico. Também é considerada como um diurético fraco e relaxante muscular (James, 1991). A teobromina (3,7-dimetilxantina), encontrada sobretudo, em produtos de cacau, tem ação diurética enquanto a teofilina (1,3-dimetilxantina), encontrada em algumas variedades de chás, tem predominantemente efeito broncodilatador (Harkins et al., 1998).

Numerosos métodos tais como espectrofotometria, titulometria e cromatografia líquida de alta eficiência (CLAE) são usados para a determinação destes alcalóides. A vantagem da CLAE na análise destes compostos incluí eficiência, sensibilidade, especificidade e rapidez (Naik, 2001). Além disso, a técnica de CLAE permite a quantificação de cada composto numa única corrida cromatográfica.

Os objetivos deste trabalho foram otimizar metodologia por CLAE para quantificar, simultaneamente, teobromina, teofilina e cafeína em chás, comparar os valo- 
res de cafeína obtidos por este método com aqueles obtidos pelo método espectrofotométrico segundo Schormüller (1970) e analisar alguns chás usualmente consumidos em nosso país usando o método por CLAE otimizado.

\section{MATERIAL E MÉTODOS}

\section{Amostras}

Para a realização deste trabalho, foram utilizadas 10 amostras de chás de diferentes marcas comerciais, sendo: 3 amostras de chá de camomila (Matricaria chamomilla L.) (C1, C2, C3), 2 amostras de chá de hortelã (Mentha arvensis L. e Mentha piperita) (H1 e H2, respectivamente), 3 amostras de chá preto (Camellia sinensis L.), tipo Assam (P1), mistura de chás do Ceilão e da Índia (P2) e aromatizado com bergamota (P3), 1 amostra de chá de boldo (Peumus boldus) (B1) e 1 amostra de chá floral composto por maçã (Pyrus malus L.), hibisco (Hibiscus sabdariffa L.), alcaçuz (Glycyrrhiza glabra L.), rosa canina (Rosa canina L.), raiz de chicória (Cichorium intybus L.) e casca de laranja (Citrus aurantium), (F1).

As amostras foram adquiridas em supermercados de Campinas (SP). Todas as amostras são de procedências nacional com exceção das amostras de chá preto P2 e P3, que são importadas, e das amostras P1 e B1, que são apenas embaladas no Brasil.

As amostras de chá em sachês foram retiradas dos mesmos e homogeneizadas e as amostras a granel foram apenas homogeneizadas.

\section{Reagentes}

Padrões de cafeína (Merck 1025840250, Alemanha), teobromina (Sigma $\left.\mathrm{N}^{\circ} \mathrm{T}-4500, \mathrm{EUA}\right)$ e teofilina (Sigma $\mathrm{N}^{\circ} \mathrm{T}-1633$, EUA) foram secos em estufa a $70{ }^{\circ} \mathrm{C}$ por 4 horas antes de serem pesados e diluídos em fase móvel para o preparo das soluções-estoque.

Os reagentes usados para extração e preparo das amostras foram de grau P.A. Para análise cromatográfica foram usados solventes de grau cromatográfico, os quais foram filtrados e desgaseificados em ultra-som sob vácuo antes do uso.

\section{Método espectrofotométrico}

\section{Extração dos alcalóides}

A metodologia utilizada para a determinação de cafeína por espectrofotometria baseou-se em Schormüller (1970) e consiste em pesar 2,0 g de amostra em um erlenmeyer e adicionar ao mesmo 5,0 g de óxido de magnésio e $200 \mathrm{~mL}$ de água destilada. Ferver a mistura por 45 minutos com agitação constante, repondo a água perdida por evaporação. Após resfriamento, filtrar a mistura para um funil de separação e adicionar $4 \mathrm{~mL}$ de $\mathrm{H}_{2} \mathrm{SO}_{4}(1+9$, $\mathrm{v} / \mathrm{v}$ em água). Extrair 5 vezes com $20 \mathrm{~mL}$ de clorofórmio, agitando vigorosamente. Recolher a fase de clorofórmio em um outro funil de separação e adicionar a este $5 \mathrm{~mL}$ de $\mathrm{KOH}$ aquoso a 1\%. Agitar por 1 minuto e deixar separar as fases. Filtrar a fase clorofórmica, através de algodão, para um balão volumétrico de $100 \mathrm{~mL}$ e completar o volume com clorofórmio. Transferir uma alíquota de $2 \mathrm{~mL}$ para um balão volumétrico de $50 \mathrm{~mL}$, completar o volume com clorofórmio e ler as absorbâncias no espectrofotômetro a 273 e $320 \mathrm{~nm}$, contra um branco de clorofórmio.

\section{Espectrofotometria}

Foi utilizado um espectrofotômetro PHILIPS modelo PU 8620 (Pye Unicam Ltd, Inglaterra).

A quantificação foi feita utilizando-se curva de calibração com 5 pontos, cujas concentrações variaram entre 0,2 e 1,0 mg de cafeína/50 mL de clorofórmio. Após a leitura das absorbâncias dos padrões contra um branco de clorofórmio, foi construído o gráfico (abs 273 - abs 320) x mg cafeína/50 mL e pelas leituras das amostras, também contra um banco de clorofórmio, foi calculada a porcentagem de cafeína de acordo com a equação:

$\%$ cafeína $=(\mathrm{mg}$ cafeína $\times 100 \times 100) /(\mathrm{g}$ de $\operatorname{amostra} \times 2 \times$ 1000)

\section{Método por CLAE}

O método por CLAE otimizado no presente trabalho foi baseado na ISO 10095 (1992), método para determinação de cafeína em café utilizando CLAE.

\section{Extração dos alcalóides}

Com base na ISO 10095 (1992), a extração dos alcalóides foi realizada de maneira muito mais simples que para o método espectrofotométrico, consistindo apenas em pesar 3,0 $\mathrm{g}$ de amostra e 6,0 $\mathrm{g}$ de óxido de magnésio em um erlenmeyer de $300 \mathrm{~mL}$ (anotar o peso inicial do conjunto: erlenmeyer + amostra + óxido de magnésio), adicionar $100 \mathrm{~mL}$ de água destilada e ferver a mistura por 15 minutos. Resfriar e pesar novamente o conjunto repondo a água perdida por evaporação até se atingir $100 \mathrm{~g}$ acima do peso inicial. Centrifugar a 2000 rpm por 5 minutos, filtrar o sobrenadante em membrana filtrante de $0,45 \mu \mathrm{m}$ e injetar no cromatógrafo líquido. 


\section{Cromatografia Líquida de Alta Eficiência}

Para a realização desta análise, foi utilizado um cromatógrafo líquido (Pharmacia LKB 2248, Alemanha) com detector UV/VIS (Pharmacia LKB 2141, Alemanha) ajustado em $273 \mathrm{~nm}$. As condições cromatográficas foram as seguintes: coluna Inertsil ODS-3 $(150 \times 4 \mathrm{~mm}, 5 \mu \mathrm{m})$ (Chrompack, Holanda) com coluna de guarda com fase reversa $(10 \times 3 \mathrm{~mm}, 5 \mu \mathrm{m})$ (Chrompack, Holanda), fase móvel de ácido acético $1 \%+$ acetonitrila $(95: 5, \mathrm{v} / \mathrm{v})$, fluxo de $1 \mathrm{~mL} / \mathrm{min}$ e alça de amostragem de $20 \mu \mathrm{L}$.

A identificação dos compostos foi realizada por comparação dos tempos de retenção das amostras com os padrões e por co-cromatografia. A quantificação foi realizada por padronização externa. A curva padrão foi construída com 5 pontos cujas concentrações variaram de 0,2 a $60,0 \mu \mathrm{g} / \mathrm{mL}$ para teobromina e teofilina e de 0,2 a $700,0 \mu \mathrm{g} / \mathrm{mL}$ para cafeína. A porcentagem de cada analito na amostra foi calculada de acordo com a equação:

$\%$ de analito $=(\mu \mathrm{g}$ de analito $\times 100) /(\mathrm{g}$ de amostra $\mathrm{x}$ 10000)

Cromatogramas típicos dos padrões e de uma amostra de chá podem ser observados nas Figuras 1 e 2, respectivamente.

\section{Avaliação do Método por CLAE}

Como o método por CLAE foi otimizado no presente trabalho, foram determinadas a recuperação e o limite de detecção para o mesmo.

A recuperação foi realizada adicionando-se quantidades conhecidas dos três alcalóides a uma amostra. Foram adicionados dois níveis com quantidades próximas aos valores encontrados nas amostras (Tabela I). Após a adição dos padrões foi realizada a extração de acordo com o item 2.4.1. O valor obtido através do método otimizado foi comparado com a quantidade real adicionada considerando também a quantidade existente na amostra. O limite de detecção de cada alcalóide foi determinado fazendo-se diluições sucessivas do padrão e da amostra até se obter a menor quantidade detectável, isto é, duas ou três vezes maior que o ruído do equipamento (Caulcutt, Boddy, 1983).

\section{Análise Estatística}

Os resultados de cafeína obtidos pelos dois métodos, espectrofotométrico e CLAE, foram submetidos a análise de variância utilizando o programa Statgraphics Statistical Graphics System.

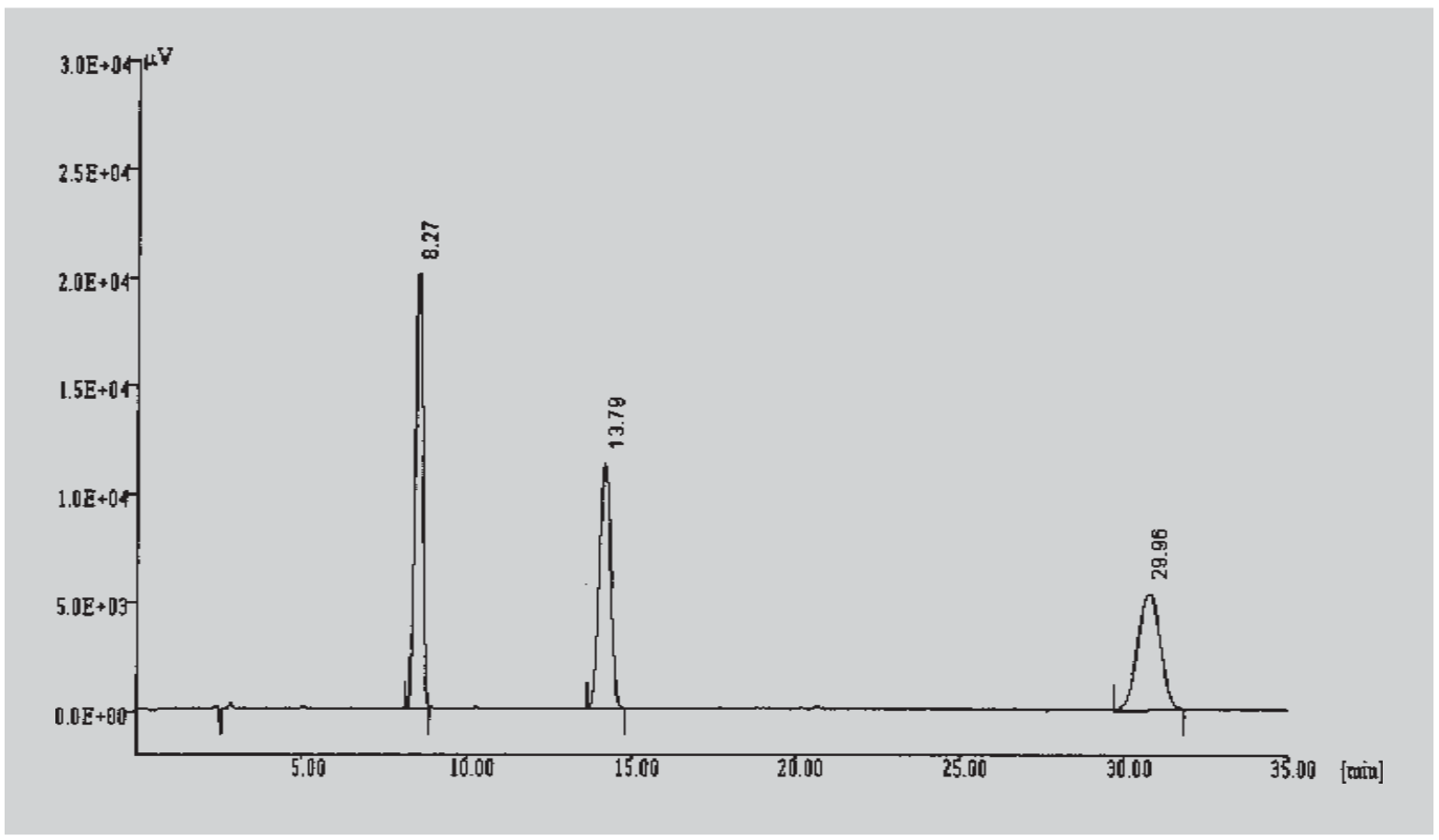

FIGURA 1 - Cromatograma típico dos padrões: teobromina (8,27 min), teofilina (13,79 min) e cafeína (29,96 min). Condições cromatográficas: coluna Inertsil ODS-3 $(150 \times 4 \mathrm{~mm}, 5 \mu \mathrm{m})$, fase móvel de ácido acético 1\% + acetonitrila $(95: 5, \mathrm{v} / \mathrm{v})$, fluxo de $1 \mathrm{~mL} / \mathrm{min}$ e comprimento de onda ajustado em $273 \mathrm{~nm}$. 


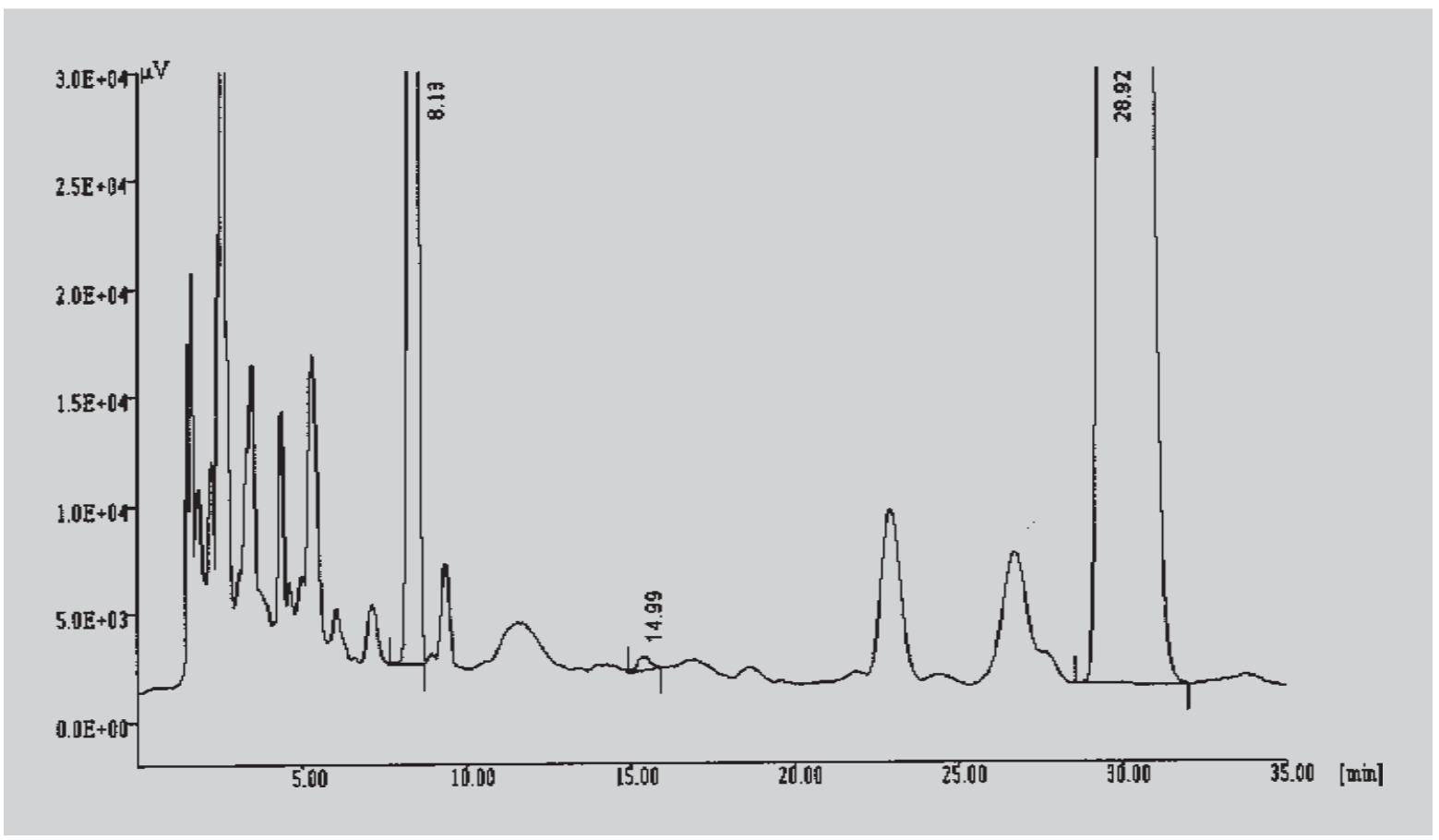

FIGURA 2 - Cromatograma típico de uma amostra de chá: teobromina (8,13 min), teofilina (14,99 min) e cafeína (28,92 min). Condições cromatográficas: coluna Inertsil ODS-3 $(150 \times 4 \mathrm{~mm}, 5 \mu \mathrm{m})$, fase móvel de ácido acético 1\%+ acetonitrila $(95: 5, \mathrm{v} / \mathrm{v})$, fluxo de $1 \mathrm{~mL} / \mathrm{min}$ e comprimento de onda ajustado em $273 \mathrm{~nm}$.

\section{RESULTADOS E DISCUSSÃO}

Os valores de recuperação e limite de detecção dos três alcalóides analisados por cromatografia líquida podem ser observados na Tabela I.

O método por CLAE, otimizado no presente trabalho, mostrou ter uma boa linearidade de instrumentação, apresentando bons coeficientes de correlação para as cur-

TABELA I - Recuperação e limite de detecção dos três compostos analisados por CLAE

\begin{tabular}{|c|c|c|c|}
\hline \multirow{3}{*}{$\begin{array}{l}\text { Nível de adição } \\
\qquad(\mathrm{g} / 100 \mathrm{~g})\end{array}$} & \multicolumn{3}{|c|}{ Recuperação (\%) } \\
\hline & Teobromina & Teofilina & Cafeína \\
\hline & Média* & Média* & Média* \\
\hline 0,005 & 98 & 100 & $\mathrm{nr}$ \\
\hline 0,01 & 92 & 96 & $\mathrm{nr}$ \\
\hline 1,0 & $\mathrm{nr}$ & $\mathrm{nr}$ & 96 \\
\hline 2,0 & $\mathrm{nr}$ & $\mathrm{nr}$ & 95 \\
\hline \multicolumn{4}{|l|}{ Limite de detecção } \\
\hline Padrão (g/100 mL) & 0,00001 & 0,00001 & 0,00002 \\
\hline $\operatorname{Amostra}(\mathrm{g} / 100 \mathrm{~g})$ & 0,0003 & 0,0003 & 0,0007 \\
\hline
\end{tabular}

*Média de duplicata; $\mathrm{nr}=$ não realizado vas de calibração $(0,99991$ para teobromina e teofilina, e 0,99995 para cafeína). Trugo et al. (1983) trabalharam com linearidades semelhantes $(0,9991$ para teobromina, 0,9998 para teofilina e 0,99997 para cafeína).

A recuperação para o método por CLAE otimizado também foi boa (média de 95\% para teobromina, 98\% para teofilina e $96 \%$ para cafeína). Valores maiores de recuperação foram obtidos por Trugo et al. (1983) para os três analitos e por Muhtadi et al. (1990) para cafeína.

Os limites de detecção obtidos por CLAE no presente trabalho $(0,0003 \mathrm{~g} / 100 \mathrm{~g}$ de amostra para teobromina e teofilina e $0,0007 \mathrm{~g} / 100 \mathrm{~g}$ de amostra para cafeína) foram menores que os estimados por Trugo et al. (1983), que apresentaram valores entre 0,05 e $0,1 \mathrm{~g} / 100 \mathrm{~g}$ de amostra, e do obtido por Hicks et al. (1996) para teofilina, que foi de $0,004 \mathrm{~g} / 100 \mathrm{~g}$ de amostra. Isso mostra que o método otimizado na presente pesquisa pode ser utilizado em amostras que contenham pequenas quantidades desses alcalóides.

Na Tabela II estão apresentados os valores de cafeína comparando os métodos espectrofotométrico e cromatográfico. Nota-se que na maioria das amostras não foi detectada a presença de cafeína pelo método por CLAE, enquanto que pelo método espectrofotométrico apenas nas amostras de chá de camomila não foi observada a presença desse alcalóide. Isso mostra que o método 
espectrofotométrico utilizado não é específico para a cafeína, quantificando também outras metilxantinas como teobromina e teofilina. No entanto, as quantidades de cafeína encontradas nas amostras de chá preto por ambos os métodos não apresentaram diferença significativa ao nível de $5 \%$, demonstrando que, dependendo da amostra, qualquer um dos métodos pode ser empregado. Por outro lado, a extração dos alcalóides para o método por cromatografia líquida é mais simples e rápida, com menos etapas, e apresenta a vantagem de não utilizar reagentes nocivos à saúde humana e ao meio-ambiente, como clorofórmio.

TABELA II - Comparação dos resultados de cafeína (g/100 g) em chás obtidos por CLAE e por espectrofotometria

\begin{tabular}{ccc}
\hline Amostra & $\begin{array}{c}\text { Método por } \\
\text { CLAE } \\
\text { Média* }\end{array}$ & $\begin{array}{c}\text { Método } \\
\text { Espectrofotométrico } \\
\text { Média* }^{*}\end{array}$ \\
\hline C1 & ND** & ND \\
C2 & ND & ND \\
C3 & ND & ND \\
H1 & ND & 0,007 \\
H2 & ND & 0,006 \\
P1 & $2,405^{\mathrm{a}}$ & $2,340^{\mathrm{a}}$ \\
P2 & $2,612^{\mathrm{a}}$ & $2,655^{\mathrm{a}}$ \\
P3 & $2,450^{\mathrm{a}}$ & $2,145^{\mathrm{a}}$ \\
B1 & ND & 0,013 \\
F1 & ND & 0,004 \\
\hline
\end{tabular}

* Média de duplicatas.

** ND = Não detectado. Limite de detecção $=0,0007 \mathrm{~g} /$ $100 \mathrm{~g}$.

$\mathrm{C} 1,2,3=$ camomila, $\mathrm{H} 1,2=$ hortelã, $\mathrm{P} 1,2,3=$ preto, $\mathrm{B} 1$ = boldo, $\mathrm{F} 1=$ floral.

Valores na mesma linha com letras iguais não apresentam diferença significativa ao nível de 5\%.

Na Tabela III estão apresentados os valores de teobromina, teofilina e cafeína obtidos pelo método cromatográfico. Observamos que, apesar de ter sido detectada a presença de teobromina em todas as amostras, somente as amostras de chá preto apresentaram quantidades significativas desse alcalóide, sendo: $0,06 \mathrm{~g} / 100 \mathrm{~g}$ para $\mathrm{P} 1$, $0,11 \mathrm{~g} / 100 \mathrm{~g}$ para $\mathrm{P} 2$ e $0,13 \mathrm{~g} / 100 \mathrm{~g}$ para $\mathrm{P} 3$. Nas demais amostras o valor máximo obtido foi de $0,003 \mathrm{~g} / 100 \mathrm{~g}$.

Em nenhuma das amostras foi encontrada quantidade relevante de teofilina, sendo que o maior teor encontrado foi de $0,002 \mathrm{~g} / 100 \mathrm{~g}$ na amostra P1.

Levando-se em conta que a composição das folhas de chá pode variar com a espécie, idade das folhas, clima
TABELA III - Valores de teobromina, teofilina e cafeína (g/100 g) em chás obtidos por CLAE

\begin{tabular}{cccc}
\hline Amostra & $\begin{array}{c}\text { Teobromina } \\
\text { Média* }\end{array}$ & $\begin{array}{c}\text { Teofilina } \\
\text { Média* }\end{array}$ & $\begin{array}{c}\text { Cafeína } \\
\text { Média* }\end{array}$ \\
\hline C1 & 0,002 & ND** & ND \\
C2 & 0,002 & ND & ND \\
C3 & 0,003 & ND & ND \\
H1 & 0,001 & ND & ND \\
H2 & 0,001 & ND & ND \\
P1 & 0,056 & 0,002 & 2,405 \\
P2 & 0,105 & 0,001 & 2,612 \\
P3 & 0,130 & 0,001 & 2,450 \\
B1 & 0,001 & ND & ND \\
F1 & 0,002 & 0,001 & ND \\
\hline
\end{tabular}

* Média de duplicatas.

** ND = Não detectado.

Limite de detecção $=0,0003 \mathrm{~g} / 100 \mathrm{~g}$ para teofilina e $0,0007 \mathrm{~g} / 100 \mathrm{~g}$ para cafeína

$\mathrm{C} 1,2,3=$ camomila, $\mathrm{H} 1,2=$ hortelã, $\mathrm{P} 1,2,3=$ preto, $\mathrm{B} 1$ $=$ boldo, $\mathrm{F} 1=$ floral

e condições de cultivo (Lin et al., 1996, 1998), podemos considerar que esses resultados se aproximam dos resultados obtidos por Hicks et al. (1996), que encontraram entre 0,164 e $0,169 \mathrm{~g} / 100 \mathrm{~g}$ de teobromina em chá preto e não detectaram a presença de teobromina, teofilina e cafeína em chás herbais. Trugo et al. (1983) encontraram valores de teobromina entre 0,09 e $0,41 \mathrm{~g} / 100 \mathrm{~g}$ em amostras de chás não especificadas. Love (1989) obteve valores entre não detectado e $0,75 \mathrm{~g} / 100 \mathrm{~g}$ para teobromina $\mathrm{e}$ entre 1,18 a $2,12 \mathrm{~g} / 100 \mathrm{~g}$ para teofilina em amostras de chás também não especificadas.

A amostra de chá floral analisada (F1) apresentou composição semelhante à das amostras de chás herbais analisados, com pequenas quantidades de teobromina $(0,002 \mathrm{~g} / 100 \mathrm{~g})$ e teofilina $(0,001 \mathrm{~g} / 100 \mathrm{~g})$ e ausência de cafeína.

Cafeína só foi detectada nas amostras de chá preto, cujos valores variaram de 2,41 a 2,61 g/100 g. Estes valores se aproximam dos encontrados por Vergnes e Alary (1986), que encontraram entre 2,58 e 3,29 g/100 g. Entre as amostras analisadas por esses autores havia uma de chá do Ceilão, na qual foi encontrado $2,58 \mathrm{~g}$ de cafeína/100 g de amostra, valor este que coincide com o resultado obtido no presente trabalho para uma amostra semelhante, P2, que é composta por chás do Ceilão e da Índia. Hicks et al. (1996) e Love (1989) também encontraram valores próximos de cafeína. O primeiro entre 3,28 e 3,66 g/100 g em 
amostras de chá preto e o segundo entre 3,16 e 3,70 g/100 $\mathrm{g}$ em amostras de chás não especificadas. Muhtadi et al. (1990) encontraram valores para cafeína em chás entre 1,3 a 3,3 g/100 g. Valores menores, variando de 0,76 a 1,74 g/ $100 \mathrm{~g}$, foram obtidos por Camargo et al. (1999) em chá preto. Lin et al. (1996) obtiveram valores maiores em chá preto tipo Assam (em média, 5,4 g/100 g), enquanto que no presente trabalho foi encontrado valor de $2,4 \mathrm{~g} / 100 \mathrm{~g}$ para amostra semelhante $(\mathrm{P} 1)$.

\section{CONCLUSÃO}

O método cromatográfico utilizado mostrou-se simples, econômico, exato e preciso para a determinação simultânea de teobromina, teofilina e cafeína em chás.

O teor de cafeína encontrado nas amostras de chá preto por ambos os métodos não apresentou diferença significativa $(\mathrm{p}>0,005)$.

Das amostras analisadas somente o chá preto continha os três alcalóides e com quantidades razoáveis de teobromina e cafeína. Já a maioria das amostras de chás herbais continha apenas pequenas quantidades de teobromina.

\section{ABSTRACT \\ Simultaneous determination of theobromine, theophylline and caffeine in teas by high performance liquid chromatography}

To carry out this study, 10 samples of different kinds and brands of teas were analyzed with the purpose of quantifying simultaneously theobromine, theophylline and caffeine. For this, high performance liquid chromatography (HPLC) was used based on ISO 10095 (1992). The conditions were: a reversed phase column (Inertisil ODS-3, 150x4 mm, $5 \mathrm{~mm}$ ); acetic acid 1\% + acetonitrile $(95: 5, \mathrm{v} / \mathrm{v})$ as mobile phase; flow of $1 \mathrm{ml} / \mathrm{min}$ and UV-VIS detector set at $273 \mathrm{~nm}$. The results of caffeine obtained by this method were compared with those using a spectrophotometric method according to Schormüller (1970). In the case of black tea, no difference was observed in the caffeine, by both methods. The samples of black tea had the highest amounts of theobromine and caffeine and no sample had a significant amount of theophylline.

UNITERMS: Alkaloids. Theobromine. Theophylline. Caffeine. Tea. HPLC.

\section{AGRADECIMENTOS}

Os autores agradecem ao Centro de Química de Alimentos e Nutrição Aplicada do Instituto de Tecnologia de Alimentos, por possibilitar a realização deste trabalho.

\section{REFERÊNCIAS BIBLIOGRÁFICAS}

CAMARGO, M. C. R. DE, TOLEDO, M. C. F. HPLC determination of caffeine in tea, chocolate products and carbonated beverages. J. Sci. Food Agric., London, v.79, p. 1861-1864, 1999.

CAULCUTT, R., BODDY, R. Statistic for analytical chemists. 1.ed. London: Chapman and Hall, 1983; p. 201-205.

HARKINS, J. D., REES, W. A., MUNDY, G. D., STANLEY, S. D., TOBIN, T. An overview of the methylxanthines and their regulation in the horse. Equine Practice. Santa Barbara, v. 20, p. 10-16, 1998.

HICKS, M. B., HSIEH, Y-H. P., BELL, L. N. Tea preparation and its influence on methylxanthine concentration. Food Res. Int., Essex, v. 29, p. 325-330, 1996.

ISO 10095:1992E - International Standard. Coffee Determination of caffeine content - Method using highperformance liquid chromatography. Geneve: International Organization for Standardization, 1992. p. 1-5.

JAMES, J. E. Caffeine \& Health. San Diego: Academic Press Inc, 1991. p. 24-32 e p. 63-85.

LIN, Y-L., JUAN, I-M., CHEN, Y-L., LIANG, Y-C., LIN, $\mathrm{J}-\mathrm{K}$. Composition of polyphenols in fresh tea leaves and associations of their oxygen-radical-absorbing capacity with antiproliferative actions in fibroblast cells. J. Agric. Food Chem., Easton, v. 44, p. 1387-1394, 1996.

LIN, J-K., LIN, C-L., LIANG, Y-C., LIN-SHIAU, S-Y., JUAN, I-M. Survey of catechins, gallic acid, and methylxanthines in green, oolong, pu-erh, and black teas. J. Agric. Food Chem., Easton, v. 46, p. 3635-3642, 1998.

LOVE, J. L. Caffeine, theophylline, and theobromine in New Zealand foods. Food Technol. N. Z., Auckland, v. 24, p. 29-31, 1989. 
MUHTADI, F. J., EL-HAWARY, S. S., HIFNAWY, M. S. Comparative HPLC and GLC determination of caffeine in different food products. J. Liq. Chromatogr., New York, v. 13, p. 1013-1028, 1990.

NAIK, J. P. Improved high-performance liquid chromatography method to determine theobromine and caffeine in cocoa and cocoa products. J. Agric. Food Chem., Washington, v. 49, p. 3570-3583, 2001.

SCHORMÜLLER, J. Handbuch der Lebensmmittelchemie. New York: Spring-Verlag, 1970. Band VI, p. 82-83 e 206-207.
TRUGO, L. C., MACRAE, R., DICK, J. Determination of purine alkaloids and trigonelline in instant coffee and other beverages using high performance liquid chromatography. J. Sci. Food Agric., London, v. 34, p. 300-306, 1983.

VERGNES, M. F., ALARY, J. Dosage des xanthiques naturales par CLHP - Comparaison des methodes et applications. Talanta, Santa Barbara, v. 33, p. 997-1000, 1986.

Recebido para publicação em 24 de janeiro de 2001. 